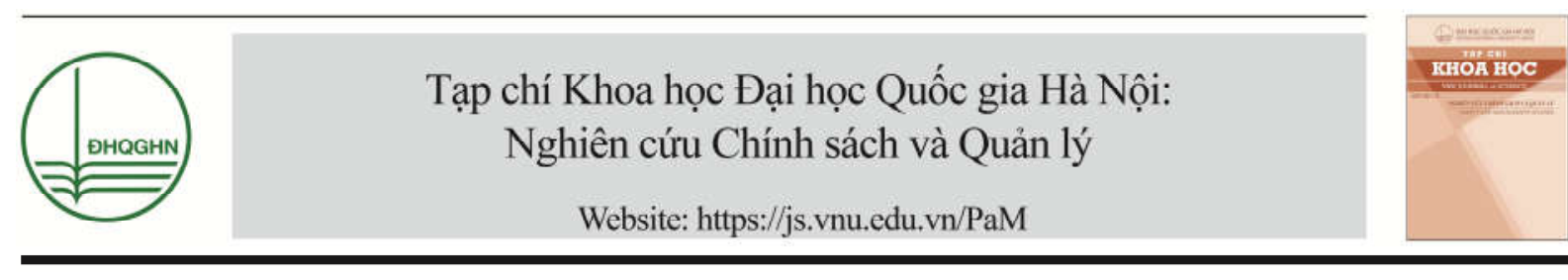

\title{
Quan điểm của Đảng, chính sách của Nhà nước về di dân các dân tộc thiểu số - Những thành quả nghiên cứu và những vấn đề đặt ra
}

\author{
Nguyễn Đình Tấn \\ Học viện Chính trị Quốc gia Hồ Chí Minh, 135 Nguyễn Phong Sắc, Nghĩa Tân, Hà Nội, Việt Nam \\ Nhận ngày 13 tháng 07 năm 2018 \\ Chỉnh sửa ngày 16 tháng 07 năm 2018; Chấp nhận đăng ngày 19 tháng 07 năm 2018
}

\begin{abstract}
Tóm tắt: Quan điểm, chủ trương của Đảng ta là nhất quán thực hiện chính sách bình đẳng, đoàn kết, tôn trọng và giúp đỡ lẫn nhau giữa các dân tộc, tạo điều kiện để các dân tộc cùng phát triển, gắn bó mật thiết với sự phát triển chung của cả cộng đồng các dân tộcViệt Nam.Đại hội Đảng lần thứ XII chỉ rõ: "Thực hiện tốt chiến lược phát triển kinh tế-xã hội ở miền núi, vùng sâu, vùng xa, vùng biên giới...làm tốt công tác định canh, định cư và xây dựng vùng kinh tế mới. Quy hoạch, phân bố, sắp xếp lại dân cư, gắn phát triển kinh tế với đảm bảo anninh, quốc phòng”. Đảng, Nhà nước ban hành các chương trình, chính sách nhằm bảo đảm cuộc sống ngày càng tốt hơn cho đồng bào các dân tộc thiểu số. Đảng, Nhà nước ban hành hàng loạt các chương trình dự án, địnhcanh dịnh cư, quy hoạch lại dân cư, "hạ sơn", di cư xen ghép nội tỉnh, nội vùng, di cư vùng núi phía Bắc- Tây Nguyên, Đông Nam Bộ nhằm không ngừng cải thiện đời sống cho nhân dân, đặc biệt là đồng bào dân tộc thiểu số ở vùng sâu, vùng xa, vùng các xã, đặc biệt khó khăn.Bài báo cũng điểm qua một số công trình nghiên cứu đã có về di dân các dân tộc thiểu số, những kết quả đạt được và những vấnđề cần phải tiếp tục đào sâu nghiên cứu. Mục tiêu chung của đề tài: Đánh giá hiệu quả tác động của các chính sác di dân, thực trạng, diễn biến tình hình di dân của các DTTS từ năm 1986 đến nay và đề xuất các giải pháp, chính sách di dân, góp phần phát triển bền vững và đảm bảo quốc phòng, an ninh vùng dân tộc đến năm 2030.
\end{abstract}

Tù khóa: Quan điểm của Đảng, chính sách Nhà nước, di dân các dân tộc thiểu số.

\section{Quan điểm của Đảng, chính sách của Nhà nước về vấn đề dân tộc}

* Đảng, Nhà nước ban hành và thực hiện các chương trình, chính sách nhằm đảm bảo

\footnotetext{
*Tác giả liên hệ. ĐT.: 84-912636069.

Email: nguyenanhtanxhh@gmail.com

https://doi.org/10.25073/2588-1116/vnupam.4145
}

cuộc sống ngày càng tốt hơn cho đồng bào các dân tộc thiểu số:

Nước ta là một quốc gia đa dân tộc, với người Kinh chiếm khoảng $87 \%$ dân số, có dân tộc chỉ vài chục ngàn người. Với đặc điểm như vậy, trong lãnh đạo, quản lý đất nước, Đảng và Nhà nước ta rất quan tâm đến vấn đề dân tộc, đề ra nhiều chủ trương, chính sách về các dân tộc thiểu số. Chủ trương nhất quán của Đảng, 
Nhà nước là thực hiện chính sách bình đẳng, đoàn kết, tôn trọng và giúp đỡ lẫn nhau giữa các dân tộc, tạo mọi điều kiện để các dân tộc cùng phát triển, gắn bó mật thiết với sự phát triển chung của cả cộng đồng các dân tộc Việt Nam. Đại hội lần thứ XII chỉ rõ: "Đoàn kết dân tộc có vị trí chiến lược trong sự nghiệp cách mạng nước ta. Tiếp tục hoàn thiện các thể chế, chính sách, bảo đảm các dân tộc, giúp nhau cùng phát triển, tạo chuyển biến rõ rệt trong phát triển kinh tế, văn hóa, xã hội vùng đồng bào dân tộc thiểu số, nhất là các vùng Tây Bắc, Tây Nguyên, Tây Nam Bộ, Tây duyên hải miền Trung" [1].

Quan điểm cơ bản của Đảng là, thực hiện tốt chiến lược phát triển kinh tế-xã hội, làm tốt công tác định canh, định cư và xây dựng vùng đồng bào các dân tộc thiểu số và đảm bảo cuộc sống cho đổng bào dân tộc thiểu số ở nơi định cư mới. Đại hội Đảng lần thứ $\mathrm{X}$ chỉ rõ: "Thực hiện tốt chiến lược phát triển kinh tế- xã hội ở miền núi, vùng sâu, vùng xa, vùng biên giới...làm tốt công tác định canh, định cư và xây dựng vùng kinh tế mới. Quy hoạch, phân bố, sắp xếp lại dân cư, gắn phát triển kinh tế với đảm bảo an ninh, quốc phòng" [2].

Trong lãnh đạo, quản lý đất nước, Đảng, Nhà nước ta đã ban hành và thực thi rất nhiều chính sách đối với đồng bào dân tộc thiểu số. Từ năm 1986 lại đây, Đảng, Nhà nước đã ban hành nhiều chính sách đối với đồng bào dân tộc thiểu số. Có những chính sách được duy trì thực hiện trong khoảng thời gian dài và thu được nhiều thành tựu như:Chương trình phát triển kinh tế- xã hội các xã đặc biệt khó khăn, vùng $x a$, vùng sâu theo quyết định 135/1998/QĐ-TTg, ngày 31-7-1998(Chương trình 135); Chương trình phát triển kinh tế-xã hội vùng đồng bằng Sông Cửu Long (Chương trình 173); Chương trình phát triển vùng đặc biệt khó khăn các tỉnh miền núi phía Bắc (Chương trình 186).

Nội dung chính của hệ thống chính sách dân tộc của Đảng, Nhà nước bao gồm: Chính sách phất triển nguồn nhân lực (đào tạo nghề, giải quyết việc làm, trợ cấp xã hội, hỗ trợ học nghề ngắn hạn, miễn giảm học phí);Chính sách phát triển kinh tế (bảo vệ rừng, tiêu thụ lâm sản); chương trình, dự án phát triển (chương trình 135, chính sách xóa đói giảm nghèo, định canh định cư...); Chính sách giáo dục, y tế và chăm sóc sức khỏe); Chính sách về môi trường, chính sách về chính trị, an ninh, quốc phòng (củng cố tiềm lực chính trị-tinh thần, củng cố tiềm lực kinh tế, tiềm lực khoa học công nghệ...).

Chính sách dân tộc của Đảng, Nhà nước bao phủ toàn bộ các lĩnh vực, các mặt của đồng bào các dân tộc thiểu số với mục tiêu tạo chuyển biến rõ rệt trong phát triển kinh tế, văn hóa, xã hội vùng có đồng bào dân tộc thiểu số, đảm bảo cuộc sống của đồng bào các dân tộc thiểu số ngày càng tốt hơn. Đó là một hệ thống chính sách tổng thể nhằm ổn định và phát triển mọi mặt đời sống của đồng bào các dân tộc thiểu số, qua đó mà ổn định dân cư. Nghiên cứu về chính sách di dân của Đảng, Nhà nước đối với đồng bào các dân tộc thiểu số cần đặt trong hệ thống chính sách mang tính tổng thể đó. Một khi, ở ngay nơi sinh sống, đời sống của người dân tộc thiểu số được đảm bảo thì sẽ gia tăng định canh định cư, hạn chế di dân tự do.

Ưu tiên phát triển kinh tế-xã hội các vùng dân tộc và miền núi, trước hết tập trung vào phát triển giao thông và kết cấu hạ tầng, xóa đói, giảm nghèo; khai thác có hiệu quả tiềm năng, thế mạnh của từng vùng, đi đôi với bảo vệ bền vững môi trường sinh thái, phát huy nôi lực, tinh thần tự lực, tự cường của đồng bào các dân tộc, đồng thời tăng cường sự hỗ trợ của trung ương và sự giúp đỡ của các địa phương cả nước.

* Cụ thể hóa những chủ trương nêu trên, Nhà nước đã có nhiều chính sách, giải pháp để phát triển kinh tế- xã hội, ổn định dân cư, đặc biệt đối với đồng bào các DTTS. Có thể kể ra một số quyết định, chỉ thịsau đây của chính phủ: Chỉ thị số 39/CT-TTg ngày 12/11/2004 của thủ tướng chính phủ về:"Một số chủ trương, giải pháp tiếp tục giải quyết tình trạng di dân tự phát"; Quyết định số 19/2003/QĐ-TTg ngày 16/9//2003 của thủ tướng chính phủ về chính sách di dân thực hiên quy hoạch, bố trí dân cư giai đoạn 2003-2010; 
Về cơ bản, việc thực hiện chính sách di dân đối với các dân tộc thiểu số được lồng ghép trong thực hiện các chương trình, dự án như: chương trình $135,32 a$....Ngày 31-7-1998, Thủ tướng Chính phủ ra Quyết định số 135/1998/QĐ-TTg, phê duyệt "Chương trình phát triển kinh tế- xã hội các xã đặc biệt khó khăn vùng dân tộc thiểu số và miền núi" (gọi tắt là chương trình 135). Theo kế hoạch ban đầu,chương trình sẽ kéo dài 7 năm và chia ra làm 2 giai đoạn; giai đoạn I từ năm 1998 đến năm 2000, giai đoạn II từ năm 2001 đến năm 2005. Tuy nhiên, đến năm 2006, Nhà nước Việt Nam quyết định kéo dài chương trình này thêm 5 năm và gọi giai đoạn 1997-2006 là giai đoạn I. Tiếp theo là giai đoạn II (2006- 2010). Nội dung chương trình:

a. Hỗ trợ phát triển sản xuất và chuyển dịch cơ cấu kinh tế, nâng cao trình độ sản xuất của đồng bào các dân tộc thiểu số.

b. Phát triển cơ sở hạ tầng thiết yếu ở các xã, thôn bản đăc biệt khó khăn.

c. Đào tạo bồi dưỡng cán bộ cơ sở, kiến thức kỹ năng quản lý điều hành xã hội, nâng cao năng lực cộng đồng. Đào tạo nghề cho thanh niên 16- 25 tuổi làm việc tại các nông trường, công trường và xuất khẩu lao động.

d. Hỗ trợ các dịch vụ, nâng cao chất lượng giáo dục, đời sống dân cư hợp vệ sinh, giảm thiểu tác hại môi trường đến sức khỏe của người dân.

Ngày 27-12-2008, Chính phủ ra quyết định 30a/2008/QĐ-CP về chương trình hỗ trợ giảm nghèo nhanh và bền vững đối với 61 huyện nghèo. Mục tiêu tổng quát là: Tạo sự chuyển biến nhanh hơn về đời sống vật chất, tinh thần của người nghèo, đồng bào thiểu số thuộc các huyện nghèo; hỗ trợ phát triển sản xuất nông, lâm nghiệp bền vững; xây dựng kết cấu hạ tầng kinh tế- xã hội phù hợp với đặc điểm của từng huyện; chuyển biến cơ cấu kinh tế và các hình thức tổ chức sản xuất có hiệu quả theo quy hoạch; xây dựng xã hội nông thôn ổn định, giàu bản sắc văn hóa dân tộc, dân trí được nâng cao, môi trường sinh thái được bảo vệ; bảo đảm vững chắc an ninh, quốc phòng. Biện pháp thực hiện: hỗ trợ sản xuất, tạo việc làm, tăng thu nhập; ban hành và thực hiện các chính sách: giáo dục, đào tạo, dạy nghề, nâng cao dân trí, đào tạo và sử dụng cán bộ; đầu tư cơ sở hạ tầng ở các thôn, bản, xã, huyện.

* Thông qua các chương trình, dự án mà Nhà nước có chương trình, dự án vềđịnh canh định cư, giảm thiểu di dân tự do với nhiều hình thức liên tục trong nhiều năm qua. Nhiều phong trào đã được phát động và để lại dấu ấn rõ rệt như: Đồng bào dân tộc "hạ sơn", di chuyển từ vùng núi cao, thiếu đất,thiếu nước xuống vùng núi thấp định canh định cư; quy hoạch lại dân cư ở các vùng miền núi; di dân xen ghép nội tỉnh; di dân xây dựng vùng kinh tế mới; tái định cư.

Về việc "hạ sơn", Đảng, Nhà nước đã chỉ đạo các cấp ủy Đảng, chính quyền địa phương lập quy hoạch ở vùng thấp để di chuyển đồng bào dân tộc thiêu số ở vùng núi cao xuống vùng núi thấp định canh định cư, quy hoạch lại dân cư ở các vùng miền núi, quy hoạch dân cư, tăng cường cơ sở hạ tầng, sắp xếp sản xuất ở vùng đồng bào dân tộc thiểu số; di dân xen ghép nội tỉnh: Đồng bào ở các địa bàn có nhiều khó khăn được chuyển cư đến ở các địa bàn ít khó khăn hơn. Các gia đình du canh du cư được tổ chức di dời xen ghép với các khu dân cư trong nội tỉnh để ổn định sản xuất và đời sống.

Di dân xây dựng vùng kinh tế mới: Chủ yếu là dòng di dân nội tỉnh và di dân Bắc- Nam, chuyển đồng bào dân tộc thiểu số từ các vùng miền núi phía Bắc vào Tây Nguyên, thực hiện bố trí lại dân cư trên phạm vi cả nước.

Di dân tái định cư: Chuyển dân từ các vùng thực hiện dự án thủy điện, khai khoáng, rừng đăc dụng, công trình quốc phòng, vùng sạt lở đẩt đai đến các vùng khác theo chương trình tái định cư.

\section{Những nghiên cứu đã có về di dân các dân tộc thiểu số, dân số tộc người và một số vấn đề đặt ra}

* Trước hết là nhũng nghiên cúu về di dân các dân tộc thiểu số:

Phải khẳng định rằng, các nhà khoa học Việt Nam chưa có nhiều các nghiên cứu về di 
dân nói chung,về di dân các dân tộc thiểu số nói riêng. Song nếu chúng ta cố gắng phân tích, chắt lọc, thì có thể rút ra một sốvấn đề có tính lý luận và thực tiễn bổ ích về di dân các dân tộc thiểu số sau:

Có những nghiên cứu trình bày một cách khách quan và khá toàn diện về các nguyên nhân dẫn đến di dân tự phát của một số đồng bào dân tộc thiểu số và đời sống của người dân di cư. Chẳng han, tác giả Trần Hữu Sơn cho rằng: Người Hmông di cư là do 3 nguyên nhân. Môt là, phương thức sản xuất của ngườiHmông đã không còn phù hợp với điều kiện đất rừng cạn kiệt, hai là, tốc độ dân số tăng dân số quá nhanh, bình quân trên đầu người thấp; $\underline{b a}$ là , đời sống của người Hmông còn gặp quá nhiều khó khăn mặc dù Đảng, Nhà nước đã hết sức chú trọng hồ trợ phát triển đời sống đồng bào các dân tộc thiểu số. Những nghiên cứu cũng chỉ ra những mặt tích cực và tiêu cực của di dân tự phát (Di cư tự do)(Nghiên cứu của tác giả Khổng Diễn). Nghiên cứu của Nguyễn Bá Thủy đã nêu rõ thực trạng di dân của các dân tộc như: Tày, Nùng, Hmông, Dao từ các tỉnh miền núi phía Bắc như Cao Bằng, Lạng Sơn vào Đắc lắc, Tây Nguyên thời kỳ (1975- 2000). Nghiên cứu này cũng phân tích những động lực, nguyên nhân và tác động của di cư đến kinh tế, chính trị, văn hóa xã hội của nơi nhập cư và xuất cư, qua đó đề xuất một số giải pháp nhằm hạn chế những tác động tiêu cực của di cư. Những nghiên cứu về chính sách di dân của tác giả Đặng Nguyên Anh, đã chú trọng đánh giá những mặt đạt được chưa đạt được của các chủ trương, chính sách di dân của chính phủ; đã đánh giá rằng: nếu di dân các tỉnh miền Bắc chủ yếu mang tính tự phát, khoảng cách ngắn, quy mô nhỏ, thì di dân tới Tây Nguyên diễn ra với quy mô và khoảng cách lớn hơn, được tổ chức một cách chặt chẽ hơn và bi chi phối bởi ý thức cộng đồng, tín ngưỡng tôn giáo. Tác giả cho rằng, di dân tới Tây Nguyên làm ảnh hưởng đến đời sống người dân sở tại, như môi trường bi ô nhiễm, tài nguyên rừng và tài nguyên nước bị xâm hại, không gian sinh tồn của người dân tộc sở tại ngày càng bị thu hẹp.Tác giả cũng khuyến cáo về việc cần phải chú trọng nhiều hơn đến đặc điểm của cộng đồng, đến nhận thức và thái độ của người dân và cán bộ địa phương sở tại. Đây Là những nghiên cứu có ý nghĩa lý luận và thực tiễn cao. Nghiên cứu của Ban tôn giáo chính phủ: "Khảo sát thực trạng một bộ phận đồng bào Hmông di dân tự do từ các tỉnh miền núi phía Bắc vào Tây NguyênNguyên nhân, kiến nghị, giải pháp" hướng vào tìm hiểu nguyên nhân của một bộ phận người Hmông theo đạo Tín Lành di cư tự do từ các tỉnh miền núi phia Bắc vào Tây Nguyên; qua đó khuyến nghị một số giải pháp nhằm bình thường hóa sinh hoạt của đạo Tín lành phù hợp với tình hình cụ thể ở Tây Nguyên. Các nghiên cứu đều cho rằng, để chính sách di dân các dân tộc thiểu số ở các tỉnh miến núi đạt hiệu quả, cần chú trọng một cách thỏa đáng đến các yếu tố văn hóa, xã hội, môi trường ở địa bàn xuất cư và nhập cư. Cần có những chính sách gián tiếp hợp lý về phân bố dân cư nhằm tạo ra những điều kiện thuận lợi cho người di cư.Nghiên cứu của Đậu Tuấn Nam và đồng sự về: "Di cư tự do của người Hmông từ đổi mới đến nay"[3] chỉ ra rằng,di cư của người Hmông là một loại hình di cư tự do đa chiều và phức tạp. Di cư có rất nhều nguyên nhân, song lý do đầu tiên và căn bản nhất chính là đói nghèo. Các lý dophi kinh tế gồm tập quán du canh du cư và di cư;vấn đề cố kết gia đình, dòng tôc; vấn đề văn hóa tộc người... Ngoài ra là các lý do khác như: lý do tôn giáo; sự bất cập trong một số chính sách phát triển và cơ chế quản lý của Nhà nước; âm mưu của các thế lực thù địch.Di cư tự do của người Hmông đã tác động đến tất cả các mặt của đời sống kinh tế, chính trị, văn hóa- xã hội tộc người; môi trường sinh thái; làm nảy sinh một số vấn đề phức tạp và nhạy cảm trong quan hệ quốc tế với các nước có chung đường biên giới; đồng thời tác động đến sự ồn định chính trị và đảm bảo an ninh quốc gia.Nghiên cứu cũng cho rằng, chỉ bằng những giải pháp hành chính sẽ không thể mang lại hiệu quả mong muốn, mà cần phải có những điều chỉnh đồng bô về kinh tế, chính trị,văn hóa- xã hội, anh ninh quốc phòng cả ở nơi xuất cư và nơi nhập cư. Nhóm tác giả đã đề xuất một loạt giải pháp khá sát hợp có ý nghĩa tham khảo và ứng dụng tốt. 
Bên cạnh những nghiên cứu về di dân các dân tộc thiểu số, vấn đề dân số tộc người là đề tài thu hút sự quan tâm nghiên cứu của các nhà nghiên cứu ngành Dân tộc học cũng như các ngành khoa học xã hội khác. Đã có nhiều công trình khoa học nghiên cứu về từng dân tộc thiểu số hay các nhóm dân tộc ở nước ta được công bố, cung cấp những nguồn tư liệu quý giá cho nghiên cứu khoa học cũng như phục vụ công tác tư vấn về chính sách dân tộc cho nhà nước.

Trong quá trình nghiên cứu, mọi khía cạnh trong đời sống tộc người như đời sống kinh tế văn hóa - xã hội cũng như các vấn đề khác như lãnh thổ tộc người, nguồn gốc, lịch sử tộc người đều được các nhà nghiên cứu quan tâm, trong đó có vấn đề dân số tộc người. Điểm qua các công trình nghiên cứu về dân số tộc người ở nước ta có thể nhận thấy số lương các nghiên cứu về vấn đề này không nhiều. Có thể điểm ra ra một số tác giả đã nghiên cứu về vấn đề này như: Mạc Đường với bài viết: "Một vài đặc điểm về di cư và dân số miền núi Hà Tây" đăng trên tạp chí Dân tộc năm 1974 [4]; Khổng diễn với cuốn sách: "Dân số và dân số tộc người ở Việt Nam"(1995). Ngoài ra ông còn có một loạt bài viết đăng trên tạp chí dân tộc học như bài viết: "Những vấn đề nghiên cứu dân số học tộc người ở nước ta" (1983), bài viết: "Vài nét về địa lý tộc người và việc nghiên cứu ở nước ta" (1981), "Về dân tộc, dân số và lao động các tỉnh miền núi phía Bắc" (1985), "Đặc điểm dân số học tộc người các tỉnh miền núi phía Bắc"(1985) [5-9]. Một công trình nghiên cứu chuyên sâu khác của Nguyễn Thế Huệ đó là cuốn sách: "Dân số các dân tộc miền núi và trung du Bắc Bộ từ sau đổi mới"(năm 2000) [10]. Tác giả Lê Huy Đại với một loạt bài báo trên tạp chí dân tộc học như: "Một số đặc điểm về phân bố dân cư ở Gia Lai- Công Tum" (1982), bài viết: "Bước đầu nghiên cứu những đặc điểm biến động dân cư tự nhiên tỉnh Đắc Lắc"(1983), bài viết: "Một vấn đề đặt ra xung quanh việc bổ sung thêm lao động để phát triển kinh tế- xã hội hiện nay ở Tây Nguyên"(1983), bài viết: "Một vài nhận xét bước đầu về đặc điểm dân số học tộc người ở miến núi Quảng nam-Đà Nẵng”(1986) [11-13]. Bài viết chung với Đặng Nghiêm Vạn: "Vấn đề dân số và phát triển của các tộc người dân số ít ở Việt Nam". Bài viết của Phan Đại Doãn: "Vài vấn đề dân số học nông thôn tiền tư bản chủ nghĩa ở Việt Nam"đăng trên tạp chí Dân tộc học [14]. Bài viết: "Một vài đặc điểm trong quá trình phát triển dân số của Việt Nam" (1984) của các tác giả Bế Viết Đằng và Khổng Diễn [15]. "Tây Nguyên vấn đề dân số và dân sinh" (1995) của Đỗ Thịnh [16].

\section{Nhũng kết quả đạt được và nhũng vấn đề đặt ra}

Như vậy có thể thấy rằng, các công trình nghiên cứu về di dân các dân tộc thiểu số cũng như các công trình nghiên cứu chuyên sâu về dân số tộc người chưa được nhiều nhà khoa học quan tâm nghiên cứu. Có thể nhận thấy, trong hầu hết các công trình đã có, chưa có công trình nào đưa ra khái niệm về di dân các dân tộc thiểu số (chưa có nghiên cứu nào định danh về di dân các dân tộc thiểu số), chưa có nghiên cứu nào một cách tổng thể, toàn diện về di dân các dân tộc thiểu số trên phạm vi toàn quốc. Do đó mà cũng chưa có nghiên cứu nào chỉ ra một phức hợp các nguyên nhân và giải pháp đồng bộ trên phạm vi cả nước; Trong hầu hết các công trình nghiên cứu về dân số tộc người ở nước ta, vấn đề xác định thành phần tộc người cũng như dân số các dân tộc và dân số của từng nhóm tộc người đã được các nhà khoa học đề cập tới, song những vấn đề liên quan đến dân số tộc người như tỷ lệ sinh- tử, sự biến động dân cư dân số trong quá trình phát triển tộc người, ảnh hưởng của phong tục tập quán đến tỷ lệ sinh, tử, đến sự phân bố dân cư...lại chưa được chú ý. Số lượng các công trình nghiên cứu chuyên sâu về dân số tộc người còn khiêm tốn, hơn nữa chỉ đăng trên tạp chí dân tộc học. Các công trình mới dừng lại ở mức chung, khái quat, cơ bản về dân số tộc người, chưa có công trình nào nghiên cứu về vấn đề dân số tộc người của một dân tộc cụ thể. Hơn nữa, hầu hết các nghiên cứu đều do các nhà dân tộc học thực hiện. Do vậy chưa mang lại một cách nhìn đa dạng, phong phú từ nhiều hướng tiếp cận Và đó chính là lý do cắt nghĩa cho việc cần thiêt phải 
có những nghiên cứu khác tiếp theo bao phủ hơn, rộng rãi hơn

\section{Tài liệu tham khảo}

[1] Đảng cộng sản Việt Nam, Văn kiện đại hội đại biểu toàn quốc lần thứ XII, NXB. CTQG, Hà Nội, 2016.

[2] Đảng cộng sản Việt Nam, Văn kiện đại hội đại biểu toàn quốc lần thứ X, NXB.CTQG, Hà Nội, 2006.

[3] Đậu Tuấn Nam. Di cư tự do người Hmông từ đổi mới đến nay. NXB. CTQG, Hà Nội, 2013.

[4] Mạc Đường: "Một vài đặc điểm về cư dân và dân số miền núi Hà Tây”. Tạp chí Dân tộc học, 1974, số 1, tr31-36.

[5] Khổng Diễn "Dân số và dân số tộc người ở Việt Nam”. NXB KHXH, Hà Nội (1995)

[6] Khổng Diễn. "Những vấn đề nghiên cứu dân số học tộc người ở nước ta". Tạp chí Dân tộc học, số 4, 1983,tr.52-55.

[7] Khổng Diễn: "Vài nét về địa lý tộc người và nghiên cứu ở nước ta". Tạp chí Dân tộc học, 1981, số 1, tr.23-28.

[8] Khổng Diễn: "Về dân tộc, dân số và lao động các tỉnh miền núi phía Bắc”. Tạp chí Dân tộc học, 1982, số 1, tr.25-30
[9] Khổng Diễn: "Đặc điểm dân số học tộc người các tỉnh miền núi phía Bắc", tạp chí Dân tộc học, 1985, số 4, tr.38-44

[10] Nguyễn Thế Huệ, Dân số các dân tộc miền núi và trung du Bắc Bộ từ sau đổi mới. NXB Văn hóa dân tộc, 2000, Hà Nội.

[11] Lê Huy Đai: "Một số đặc điểm về phân bố dân cư ở Gia Lai- Công Tum”. Tạp chí Dân tộc học, 1982, số 3.

[12] Lê Huy Đại: "Một số vấn đề đặt ra xung quanh việc bổ sung thêm lao động để phát triển kinh tếxã hội hiện nay ở Tây Nguyên". Tạp chí Dân tộc học, số 3 .

[13] Lê Huy Đại: "Một vài nhận xét bước đầu về đặc điểm dân số học tộc người ở miền núi Quảng NamĐà Nẵng”. Tạp chí Dân tộc học, số 2, tr.37-48.

[14] Phan Đại Doãn: "Vài vấn đề về dân số học nông thôn tiền TBCN ở Việt Nam, tạp chí dân tộc học 1983, số1, tr 27-31

[15] Bế Viết Đẳng, Khổng Diễn: "Một vài đặc điểm trong quá trình phát triển dân số ở Việt Nam".Tạp chí dân tộc học 1984, số 4, tr1-14

[16] Đỗ Thịnh: "Tây Nguyên vấn đề dân số và dân sinnh”. Tạp chí Dân tộc học 1995, số 1, tr 26- 28

\title{
The Party's Viewpoints and Government's Policies on the Migration of Ethnic Minority Groups: Achievements and Problems
}

\author{
Nguyen Dinh Tan \\ Ho Chi Minh National Academy of Politics, 135 Nguyen Phong Sac, Nghia Tan, Hanoi, Vietnam
}

\begin{abstract}
The Party's viewpoints and policies are consistent with the policies of equality, solidarity, mutual respect and mutual assistance among ethnic groups, creating conditions for ethnic groups to develop together with the development of the whole community of ethnic groups in Vietnam. The Party and the government have promulgated several programs and policies aimed at ensuring better life for ethnic people. The programs and projects focused on settling population replanning, re-settling people from high mountainous areas to lower areas; inter-provincial, intraregional migration, and migration in the North-Central Highlands and Southeast region to improve the living standards of the people, especially ethnic minorities in remote and mountainous areas. This paper also examines some of the existing studies on ethnic minority migration, achievements and
\end{abstract}


issues that need to be further explored. The overall objective of the paper is to assess the effectiveness of migration policies, the situation of migration of ethnic minorities from 1986 to present and to propose possible solutions and migration policies to contribute to sustainable development and ensure national defence and security of ethnic minority areas until 2030.

Keywords: Party's viewpoints, government's policies, migration of ethnic minority groups. 